\title{
Design and Performance Analysis of Active and Passive Cell Balancing for Lithium-Ion Batteries
}

\author{
Rakshak Udupa T S ${ }^{1}$, Shashank K Holla ${ }^{2 *}$ and Kariyappa B S $^{3}$. \\ ${ }^{1}$ Dept of Electronics and Communication, RV College of Engineering, India, \\ ${ }^{2}$ Dept of Electronics and Communication, RV College of Engineering, India, \\ ${ }^{3}$ Dept of Electronics and Communication, RV College of Engineering, India \\ 1'rakshaktsudupa@gmail.com, ${ }^{2}$ shashankholla@outlook.in, ${ }^{3}$ kariyappabs@rvce.edu.in
}

\begin{abstract}
Electric Vehicles (EV) are growing areas of research since the demand for clean transportation is ever-increasing. Batteries form an integral part of EVs. Battery Management systems (BMS) need to support many features, including charge balancing to improve battery life and longevity. Among passive cell balancing and active cell balancing, the latter provides better battery life and efficiency. Among different active and passive cell balancing techniques, popular techniques like Flyback transformer based active cell balancing and switched capacitor based active cell balancing is used. These methods are not only easy to implement but also provide good performance. These balancing circuits are integrated with non-ideal RC models of a lithium-ion battery. The bleed resistor based passive cell balancing took more than 16000 seconds to reach a $0.01 \mathrm{~V}$ difference for capacitors with $5 \mathrm{~F}$ capacitance, whereas the switched capacitor design is estimated to take 500 seconds. The multi-winding flyback active cell balancing system reached a $2 \%$ difference in SOC in 1800 seconds. There was a visible increase in time taken for balancing the cells using multi-winding active cell balancing as the cell temperature increased. A 2.32\% increase in the time taken for balancing the cells was observed when cell temperature increased from $293 \mathrm{~K}$ to $313 \mathrm{~K}$.
\end{abstract}

Keywords:Active, passive, Cell balancing, Battery Management Systems, Lithium Ion, multi-winding, flyback, switched capacitor

\section{Introduction}

Electric vehicles are an effective replacement for the current fossil fuel-based vehicles that produce harmful emissions. These electric vehicles are composed of six major components: chassis, motor, motor controller, batteries, Battery Management System (BMS) and driver assistance systems. Batteries are the powerhouse of these vehicles, and managing them is crucial in terms of safety and efficiency. The BMS takes care of this. Figure 1 shows the major features of a BMS. It includes thermal management, cell balancing and power limiting.

Each cell in a battery stack contributes to the overall system capacity. It has to be noted that all batteries are not manufactured identically. Batteries manufactured by the same manufacturer with the same physical size, chemistry, and shape can have different internal resistances, self-discharge rates, and capacities. The ageing factor is also observed to be different for different cells. Cell balancing is necessary as it affects the life of batteries connected in series [1],[2]. While charging, cells with higher State-Of-Charge (SOC) are stressed more, whereas while discharging, cells with lower SOC are stressed. This necessitates a cell balancing mechanism [3],[4].

The two main types of cell balancing techniques are active and passive. While passive cell balancing aims to balance all cells by discharging cells with higher SOC to lower SOC, active cell balancing tries to redistribute charge to equalize SOC. This general concept is depicted in Figure 2. 


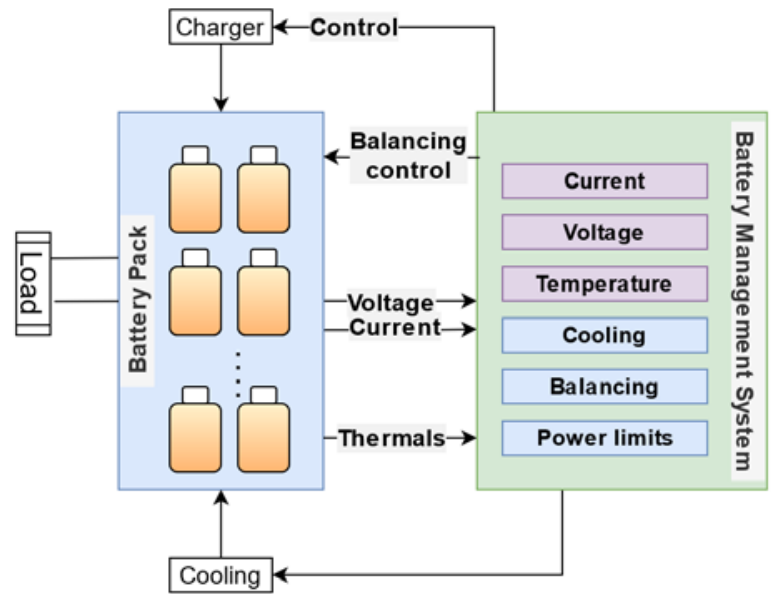

Figure 1. Typical battery management system

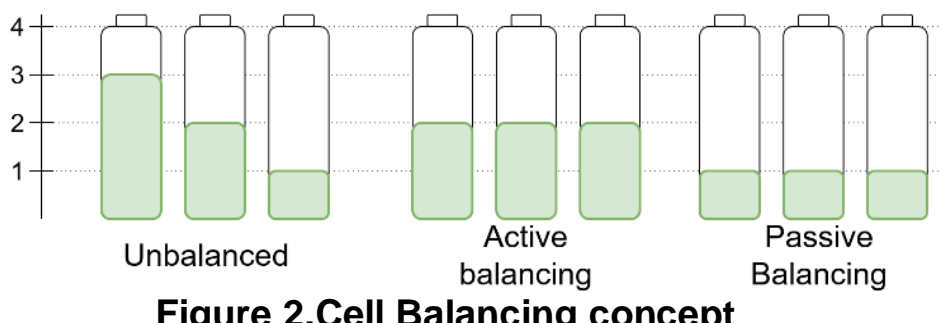

\section{Passive Balancing}

The following sections describe the design and simulation of passive cell balancing technique in MATLAB Simulink. MATLAB Simulink is a software simulation tool that helps in designing and simulating electrical circuits.

\subsection{Design of the bleed resistor passive cell balancing circuit}

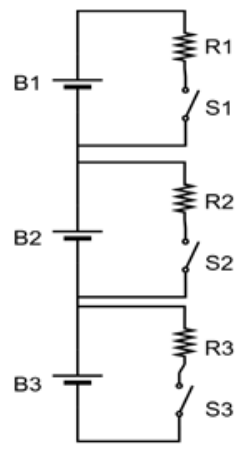

Figure 2.Bleed resistor passive cell balancing circuit

A battery stack may be reasonably balanced initially, but due to elevated temperature, ageing, and charge and discharge cycles, the balance in SOC between cells is degraded. Bleed resistor based passive cell 
balancing employs resistors and switches to dissipate the charge on cells with higher SOCs. A small amount of energy is drained from high SOC cells by using low amounts of current during the charging phase to ensure that all cells charge to their maximum SOC.

The most common way to balance a cell stack with unequal SOCs is by using a shunt resistor [5],[6]. The battery management system controls this parallel path to discharge the cell by taking in various inputs. The design employs a resister and a switch (here, a MOSFET) parallel to the battery.

Passive cell balancing is accomplished by using a switch and bleed resistor in parallel with each battery cell (Figure 3). Here B1, B2, B3 are the batteries and R1, R2, and R3 are the bleed resistors. A pulse generator drives the MOSFET's gate. When the pulse is in a high state, the cellsdischarge through the resistor. All cell voltages are continuously monitored. When a cell with maximum voltage is greater than the cell with minimum voltage, discharging of that cell is initiated. The disadvantage of passive cell balancing is that energy lost by a cell is not used to charge other cells. This leads to poor efficiency. Another disadvantage is that all cell voltages need to be continuously monitored. However, this technique is cheap and straightforward.

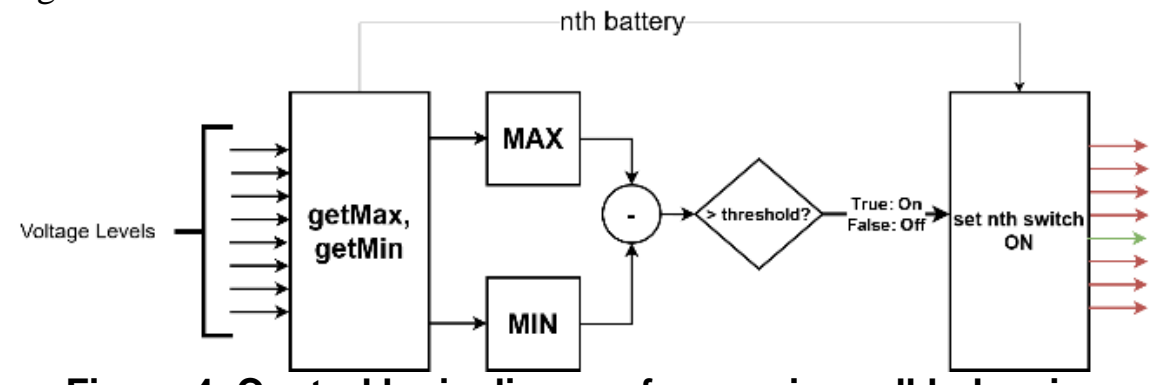

Figure 4. Control logic diagram for passive cell balancing

The control logic is shown in Figure4. It works by first reading in all cell voltages (here it is the capacitor voltages). Then the maximum voltage ( $\mathrm{m}^{\text {th }}$ cell) and the minimum voltage $\left(\mathrm{n}^{\text {th }}\right.$ cell) is subtracted and checked if it is above some set threshold. If it is so, then the maximum voltage cell's ( $\mathrm{m}^{\text {th }}$ cell) switch is turned on to discharge through the bleed resistor.

\subsection{Simulation results}

The circuit was designed and implemented, as shown in Figure5. The MATLAB function block takes in the voltage readings and controls the 8 switches. The control logic discussed in the previous section (as shown in Figure4) is modelled as a MATLAB functional block.

Figure 6 is the output of the simulation done in MATLAB. From the graph, we can observe that the cell with maximum voltage is discharged first. Whenever a cell has its voltage higher than other cells, it is discharged. As time progresses, we observe that all cells are discharged to match the cell with the lowest voltage. The cell with the lowest voltage is not set to discharge.

However, it discharges slowly over time as any practical cell would degrade over time. The eight cells, modelled as capacitors with initial voltages, slowly discharge through the bleed resistor until they meet the lowest cell voltage. 

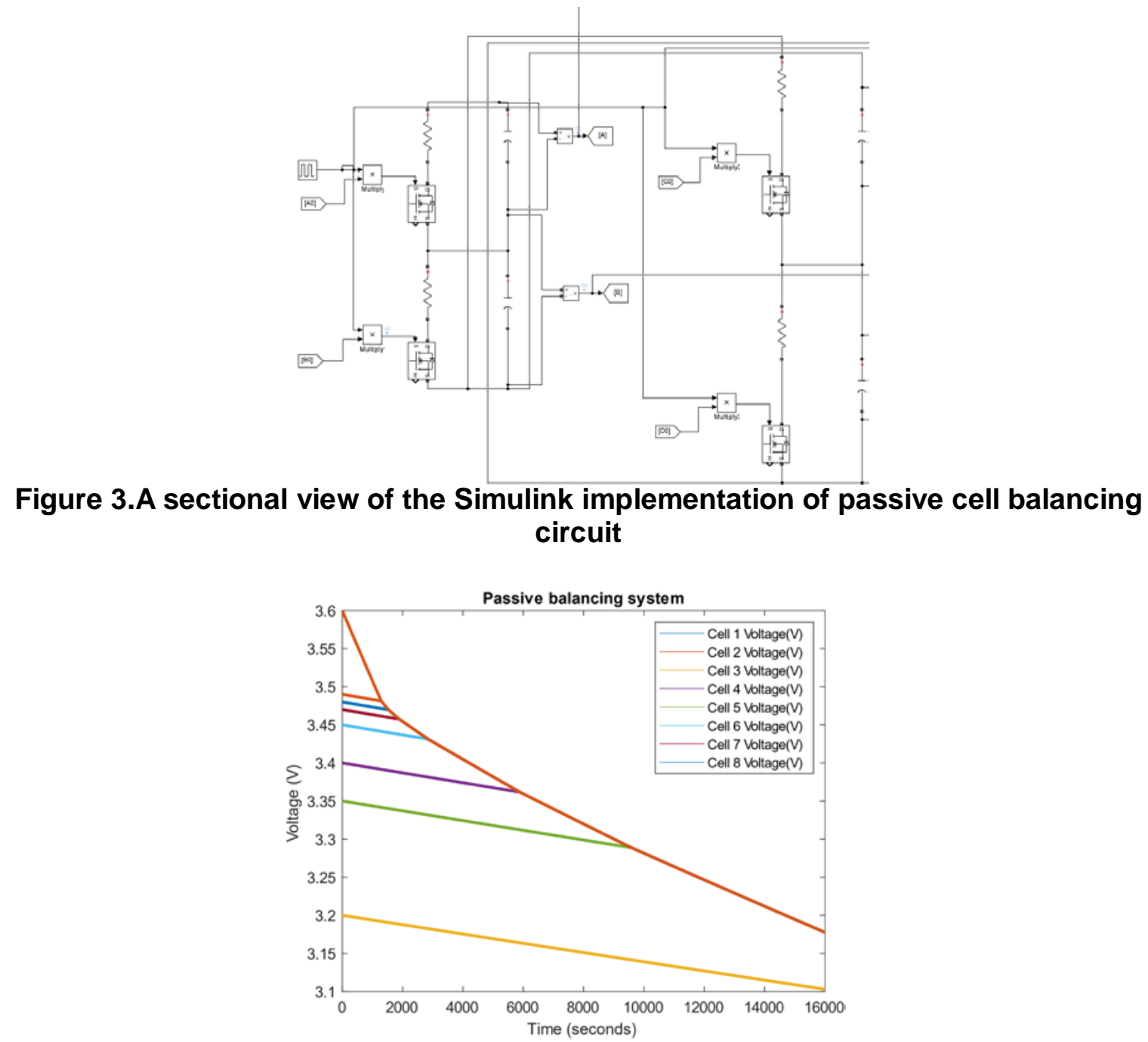

Figure 4.Voltage vs Time graph of passive cell balancing system

\section{Resonant Switched capacitor active cell balancing}

The following sections describes the design and simulation of resonant switched capacitor active cell balancing technique in MATLAB Simulink.

\subsection{Design of the resonant switched capacitor active cell balancing}

Switched capacitor active cell balancing technique provides a low cost, compact solution for active balancing of cells. However, it has some disadvantages, like a higher cost for many cells and poor balancing time. To improve this performance from conventional designs, [5] discussed a resonant circuit-based design. The circuit in Figure7 has switches made up of MOSFETS controlled by a pulse width modulated signal. The control signals for odd switches (S1, S3...) and even switches (S0, S2...) are complementary.

The pulse-width modulated (PWM) signal is driven at a duty cycle of $50 \%$ with frequency f given by $\mathrm{f}=1 / \sqrt{ }$ (LC). The operation of the system can be divided into two stages. In stage 1, the odd switches are turned on by a HIGH signal at the gates of the MOSFETS. This charges the resonant circuits. Figure8 depicts the control logic. The odd and even switches are alternatively turned on until the cell voltages are below a fixed threshold. 
Balanced state is determined by the cell voltage differences. Once the balanced state is reached, the system is turned off.

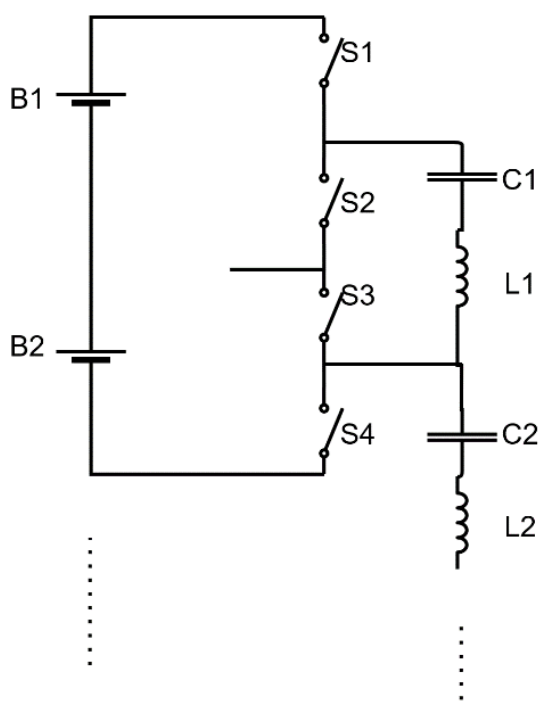

Figure 5. Resonant switched capacitor active cell balancing circuit

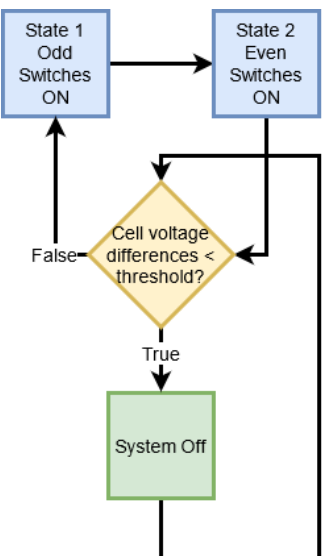

Figure 6. Resonant switched capacitor logic diagram

\subsection{Simulation results}

Figure9 shows the implementation of the resonant switched capacitor battery balancing in Simulink. The [O] and the [E] tags are controlled by a MATLAB functional block driven by the logic explained in Figure8. A very small capacitance of $0.001 \mathrm{~F}$ was chosen to simulate this circuit since the simulation time was observed to be too much for higher values of capacitance. Thus, the results can be extrapolated by saying that a $5 \mathrm{~F}$ capacitor would take 5000 times longer than a $0.001 \mathrm{~F}$ capacitor to reach the same balanced state.As shown in the output graphs in Figure10, the 6 cell voltages converge to a common average. 6 capacitors were set at different initial voltages, ranging from $3 \mathrm{~V}$ to $3.5 \mathrm{~V}$. They converged to an average voltage of around $3.25 \mathrm{~V}$. 


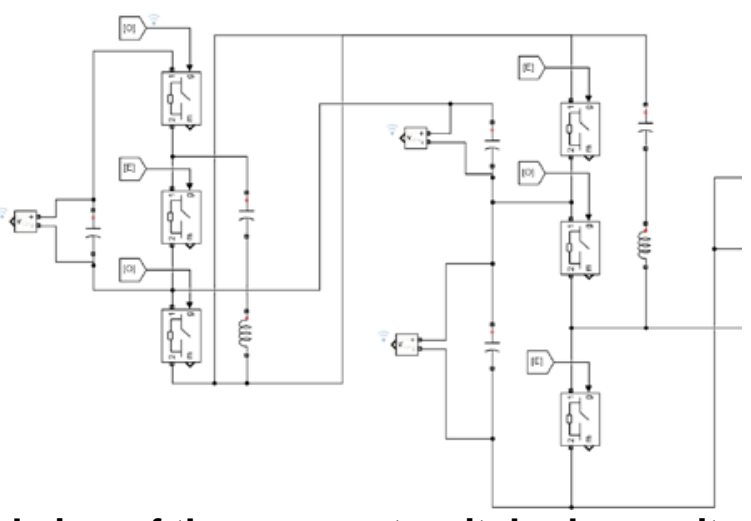

Figure 8. A sectional view of the resonant switched capacitor battery balancing Simulink schematic

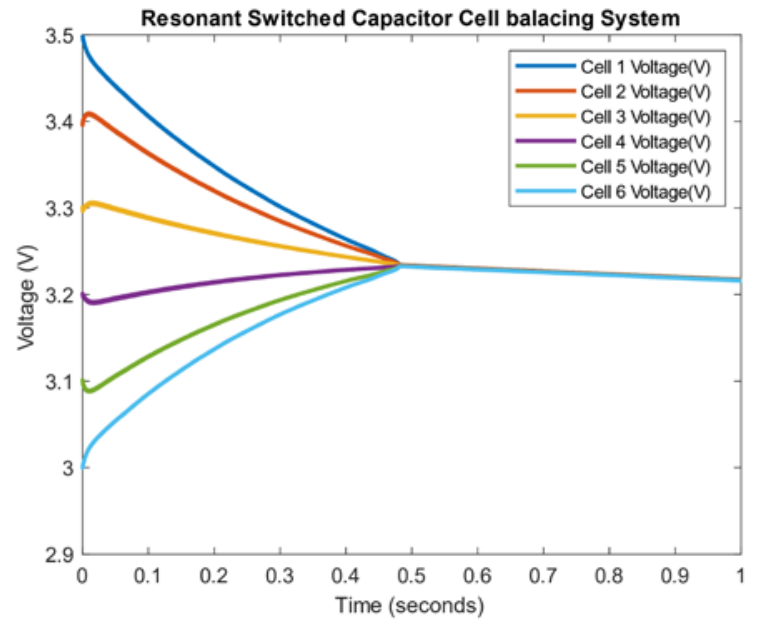

Figure 7. Voltage vs Time graph of resonant switched capacitor battery balancing

\section{Multi-winding flyback active cell balancing}

The multi-winding flyback active cell balancing circuit is initially designed and integrated with a realistic model of a lithium-ion cell. The lithium-ion cell is modelled using an RC equivalent circuit.

\subsection{Approach of modelling lithium-ion cell}

Various models have been described in the literature to predict the behaviour of batteries, which can be generally categorized into electrochemical models and equivalent circuit models [7],[8].Instead of using a capacitor as a charge storage device, an actual lithium-ion battery can be modelled. This improves the accuracy of the analysis. Like how most electrical characteristics can be modelled using RC networks, a lithium-ion cell can also be modelled by using such a combination of RC elements. Based on the model's complexity, 1 or 2 levels of RC blocks are used. Using more blocks, although may result in better accuracy, will lead to higher computation time. Figure 11 and Figure 12 show the different approaches to model it. 


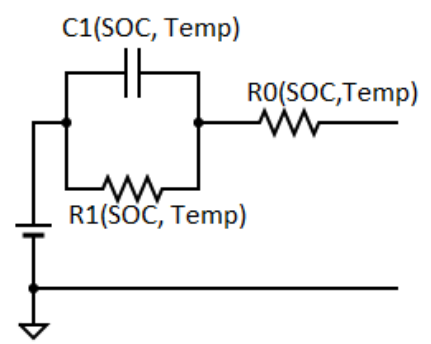

\section{Figure 9. Single stage RC model of Lithium-Ion battery}

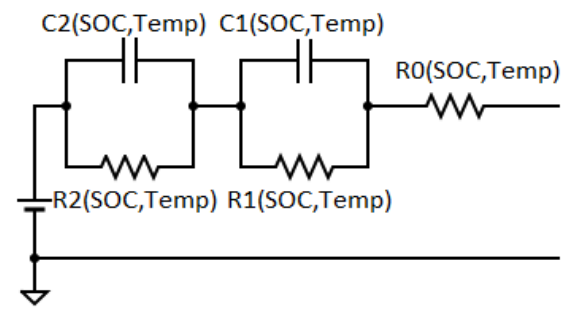

Figure 10. Two stage RC model of Lithium-Ion battery

The model allows us to validate the system's capability by accurately simulating a lithium-ion battery's current-voltage and SOC relationship by considering the thermal properties. There are several ways to model a cell [7]. One of them is a single-stage RC model, called the first-order RC model, which has a $\mathrm{V}_{\mathrm{oc}}$ that determines the cell's open-circuit voltage and R0, which determines the ohmic connection resistance. The resistor R1 is called the polarization resistance, whereas the capacitance $\mathrm{C} 1$ is called the polarization capacitance. This parallel combination of resistor and capacitor allows modelling a non-linear response of the battery.

The SOC of the cell is measured using the Coulomb counting algorithm along with an error elimination method by using the State of Charge-Open Circuit Voltage correlation curve (Figure 13). Coulomb counting tries to calculate the amount of charge that has flown into and out of the battery. However, it fails to consider the charge lost inside the battery due to parasitic reactions and self-discharging currents. Thus, to improve the accuracy of such a measurement, coulomb counting needs to be accompanied by error correction methods to compensate for the errors periodically. Experimentally modelled 31Ah lithium-ion cells of the $\mathrm{LiNi}_{\mathrm{x}} \mathrm{Mn}_{\mathrm{y}} \mathrm{Co}_{\mathrm{z}} \mathrm{O}_{2}(\mathrm{NMC})$ chemistry is used [8][10]. 


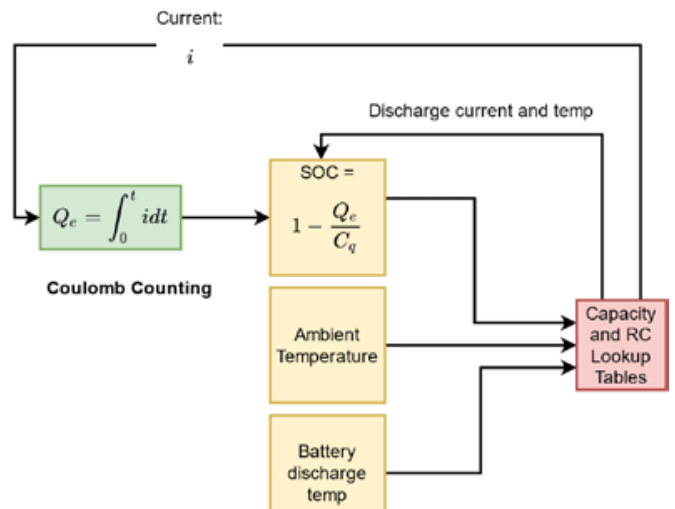

Figure 13. SOC and lookup table logic for lithium-ion cell modelling

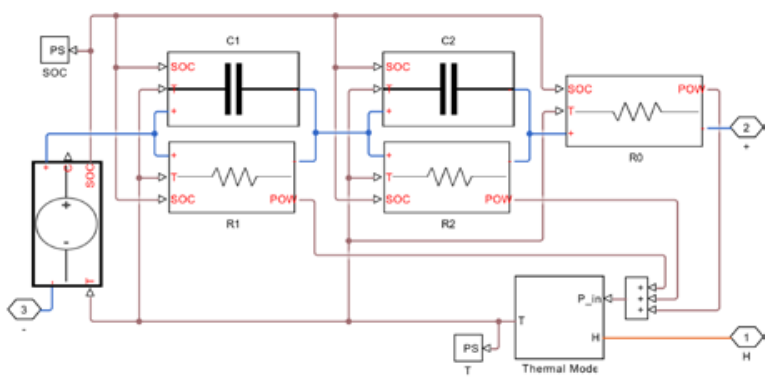

Figure 14.RC model of lithium-ion cell in MATLAB Simulink

A lookup table is derived by modelling this cell accurately. The RC values thus obtained are filled in a lookup table. For any given SOC and Temperature, a particular set of R0, R1, R2, C0, C1, Em are obtained. Linear interpolation is then used in the Simulink blocks to obtain intermediate unknown R, C, Em values. Figure 14 shows how the same model is built and simulated in MATLAB Simulink.

Tables 1,2 and 3 show the lookup tables used to model the cell for C0, R0 and VOC. Similar tables can be obtained [8]. Each cell in lookup table corresponds to a specific SOC and Temperature value.

Table 1. Capacitor 0 capacitance(F) lookuptable

\begin{tabular}{|c|c|c|c|c|c|c|c|}
\hline & & \multicolumn{6}{|c|}{ Temperature (K) } \\
\hline & & 253.15 & 258.15 & 263.15 & 273.15 & 293.15 & 313.15 \\
\hline \multirow{6}{*}{$\frac{\mathscr{0}}{\stackrel{0}{0}}$} & $\mathbf{0}$ & 14 & 78 & 21 & 115 & 27539 & 13861 \\
\hline & 10 & 44695 & 212996 & 143644 & 361717 & 346974 & 362745 \\
\hline & 20 & 1268 & 414 & 216 & 3876 & 3623 & 75454 \\
\hline & 50 & 208 & 103 & 222 & 847 & 886 & 39630 \\
\hline & 75 & 36 & 163 & 492 & 1921 & 5320 & 58952 \\
\hline & 100 & 3156 & 14964 & 29348 & 68274 & 68279 & 256576 \\
\hline
\end{tabular}

Table 2. Resistor 0 resistance(OHM) lookuptable

\begin{tabular}{|l|l|l|l|l|l|l|l|}
\hline & & \multicolumn{6}{|c|}{ Temperature (K) } \\
\hline & & 253.15 & $\mathbf{2 5 8 . 1 5}$ & $\mathbf{2 6 3 . 1 5}$ & $\mathbf{2 7 3 . 1 5}$ & $\mathbf{2 9 3 . 1 5}$ & $\mathbf{3 1 3 . 1 5}$ \\
\hline$\frown$ & $\mathbf{0}$ & 0.0475 & 0.0304 & 0.0276 & 0.0148 & 0.0124 & 0.0019 \\
\hline
\end{tabular}




\begin{tabular}{|c|c|c|c|c|c|c|c|}
\hline & & \multicolumn{7}{|c|}{ Temperature (K) } \\
\hline \multirow{2}{*}{$\mathbf{1 0}$} & 0.0539 & 0.0450 & 0.0280 & 0.0121 & 0.0116 & 0.0023 \\
\cline { 2 - 7 } & $\mathbf{2 0}$ & 0.0655 & 0.0400 & 0.0254 & 0.0171 & 0.0243 & 0.0075 \\
\hline $\mathbf{5 0}$ & 0.0439 & 0.0276 & 0.0256 & 0.0116 & 0.0062 & 0.0038 \\
\hline $\mathbf{7 5}$ & 0.0537 & 0.0389 & 0.0252 & 0.0116 & 0.0214 & 0.0055 \\
\cline { 2 - 7 } & $\mathbf{1 0 0}$ & 0.0471 & 0.0443 & 0.0245 & 0.0123 & 0.0389 & 0.0010 \\
\hline
\end{tabular}

Table 3. $\quad V_{\text {oc }}(\mathrm{V})$ lookuptable

\begin{tabular}{|c|c|c|c|c|c|c|c|}
\hline & & \multicolumn{6}{|c|}{ Temperature (K) } \\
\hline & & 253.15 & 258.15 & 263.15 & 273.15 & 293.15 & 313.15 \\
\hline \multirow{6}{*}{$\frac{\text { ڤ̊ }}{2}$} & $\mathbf{0}$ & 3.238 & 3.199 & 3.189 & 3.101 & 3.029 & 3.142 \\
\hline & 10 & 3.309 & 3.363 & 3.344 & 3.245 & 3.23 & 3.235 \\
\hline & 20 & 3.35 & 3.252 & 3.256 & 3.268 & 3.295 & 3.297 \\
\hline & 50 & 3.267 & 3.271 & 3.276 & 3.287 & 3.343 & 3.316 \\
\hline & 75 & 3.303 & 3.279 & 3.289 & 3.308 & 3.345 & 3.338 \\
\hline & 100 & 3.315 & 3.314 & 3.317 & 3.34 & 3.367 & 3.338 \\
\hline
\end{tabular}

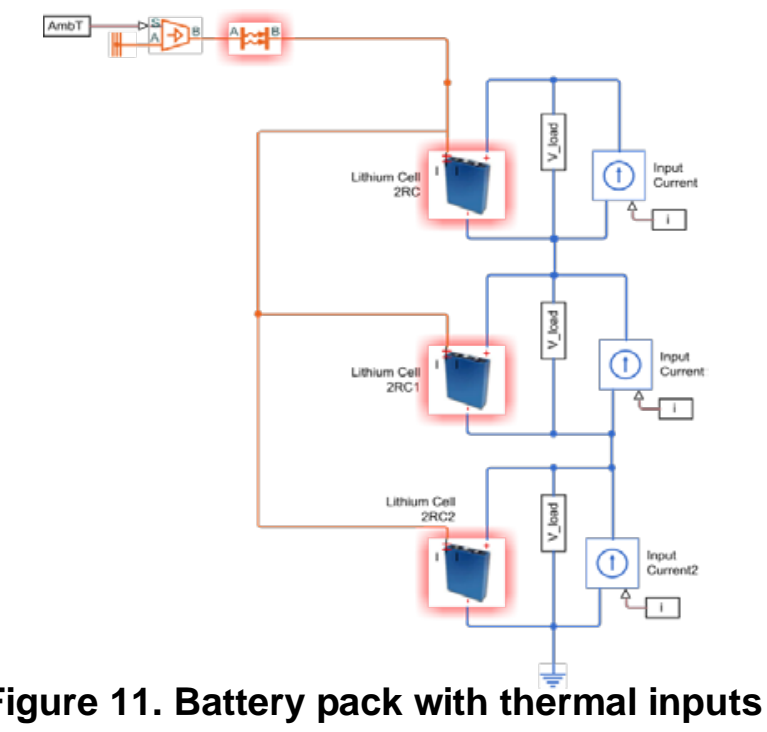

The thermal model of the cell is shown in Figure15. The ambient temperature is set to some value which is used to pick the RC values from the lookup table. The current flowing into the capacitor is given to the realistic RC model of lithium-ion cell.

\subsection{Design of the multi-winding flyback active cell balancing}

Lithium-ion cells should not be overcharged. Thus, the major tasks of a BMS would be to monitor and control the charging process. It has to ensure that the cells are balanced on reaching some threshold [11],[12].

By using a multi-winding flyback active cell balancing technique, energy can be transferred from cells with high SOC to cells with low SOC efficiently. Transformer based implementations have some good advantages. One can achieve galvanic isolation and high efficiency with a relatively easy implementation [11],[12] by using transformerbased solutions.

Two variations of the multi winding flyback converters are popular. One way is to use a multi winding transformer with the primary side connected across the whole battery pack [13]. The secondary connections are each connected across one cell with a switch to control the connection. The complete battery pack first charges the 
primary side. The energy is then transferred to the secondary side's battery with the lowest SOC first. Another way could be to enable the switch of the cell with the highest SOC so that this energy can then be transferred to the whole battery pack.

A second variation of the multi-winding flyback converter is discussed in detail. Figure16 shows the architecture of the system. It has a much easier control mechanism since only one switch needs to be driven. Initially, the switch is turned ON to charge the primary side of the transformer with the complete battery pack. Here three cells are shown to form the battery pack. Then, the switch is turned off. Since the secondary coils are similar with the same number of turns, hence the same resistance, the battery with the lowest SOC draws more current, thus charging it faster. In the same sense, charging currents of batteries at higher SOCs is lesser and thus charge slower.

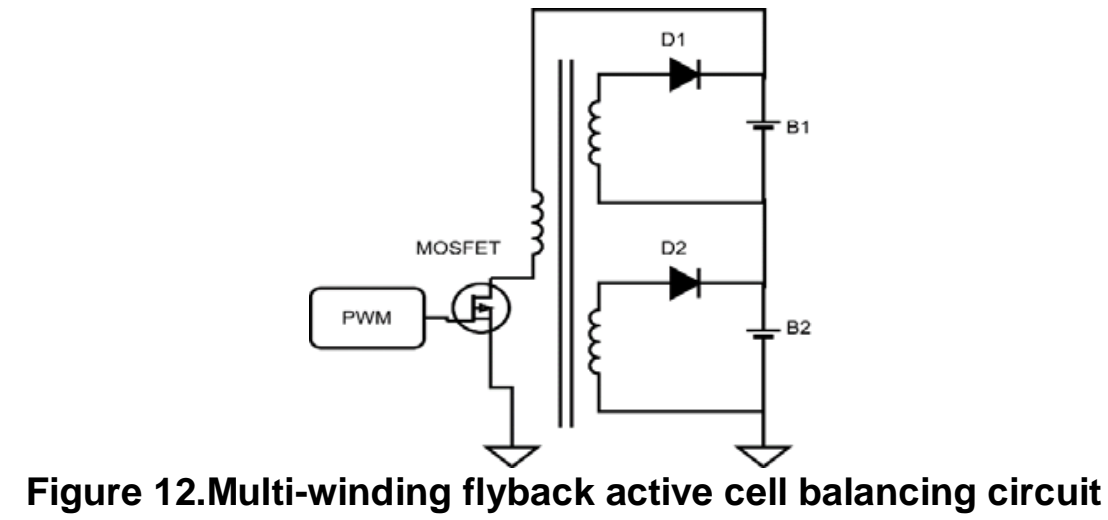

\subsection{Simulation Results}

The circuit was designed in MATLAB Simulink (Figure17) and simulated. A similar circuit with multi-winding transformer can be designed [14],[15]. The initial SOC of the three batteries was set to different values. Figure18 shows three cells, with initial SOCs of $85.6 \%, 82 \%, 80.8 \%$. Figure 18 shows the output of the simulation. It can be seen that the SOCs approach to an equal value with a maximum difference of $1 \%$. This was simulated at an initial battery temperature of $313 \mathrm{~K}$. It can be seen that the equalization time is around 2200 seconds.

The Figure19 shows that the equalization time is dependent on the battery temperature. One can observe that the equalization time increases with increasing battery temperature. 


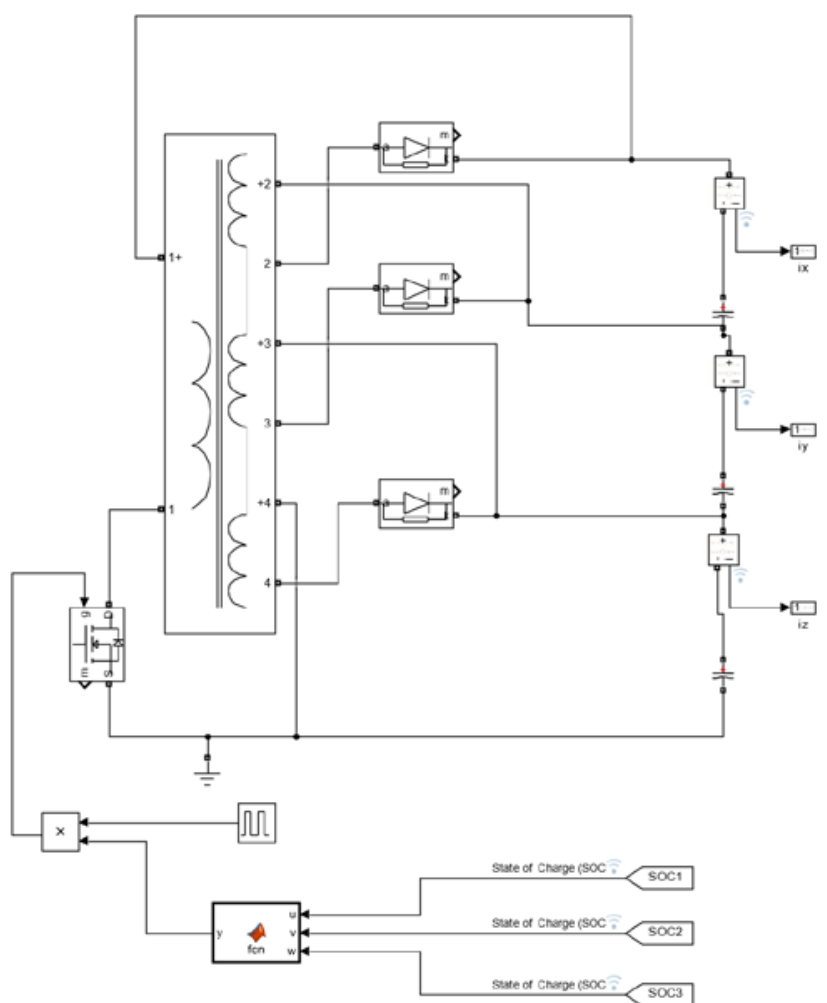

Figure 13. MATLAB Simulink implementation of multi-winding flyback active cell balancing circuit

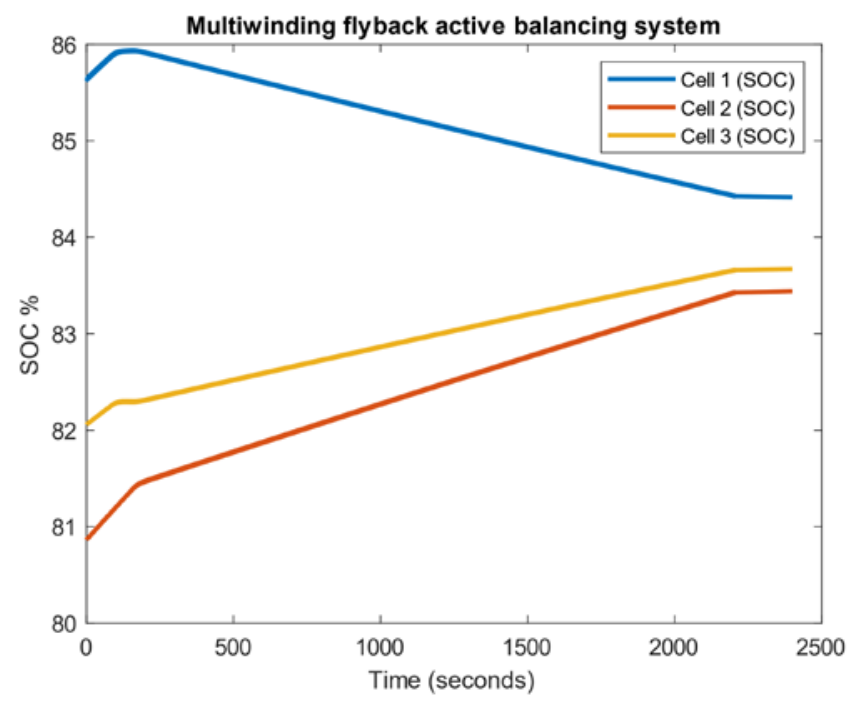

Figure 14. SOC vs Time graph for multi-winding flyback active cell balancing system 


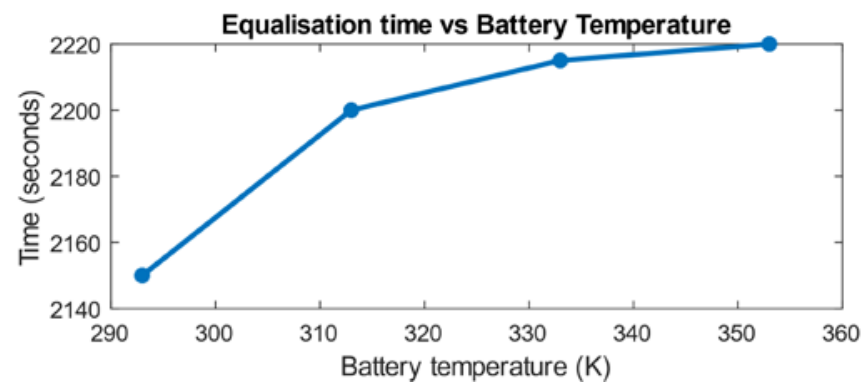

Figure 15. Time vs Battery temperature for multi-winding flyback active cell balancing system with RC model of Lithium-Ion cell

\section{Comparison between different cell balancing implementations}

After implementing the three different techniques in the previous sections, a comparison can be made regarding the designs. Although passive balancing technique is simple to implement, active flyback-based solutions provide better efficiency and performance. This is summarized in Table 4.

Table 4. Comparison of active and passive cell balancing techniques

\begin{tabular}{|c|c|c|c|}
\hline Factors & Passive bleed resistor & Active switched capacitor & Active Flyback \\
\hline Cell type used & Ideal capacitor (5F) & Ideal capacitor (0.001F) & $\begin{array}{c}\text { RC Model of Lithium-Ion cell } \\
\text { (31Ah) }\end{array}$ \\
\hline $\begin{array}{c}\text { Initial } \\
\text { conditions }\end{array}$ & $\begin{array}{c}\text { Capacitors with initial voltage } \\
\text { ranging from 3V to 3.6V }\end{array}$ & $\begin{array}{c}\text { Capacitors with initial voltage } \\
\text { ranging from 3V to 3.6V }\end{array}$ & $\begin{array}{c}\text { Lithium-Ion cell with initial SOC } \\
\text { ranging from 81\% to 86\% }\end{array}$ \\
\hline $\begin{array}{c}\text { Balancing } \\
\text { time }\end{array}$ & 16000 seconds & 0.5 s for 0.001F, 500s for 5F & 2200 seconds at 313K \\
\hline $\begin{array}{c}\text { Monitoring of } \\
\text { cell }\end{array}$ & Required always for all cells & $\begin{array}{c}\text { The design monitors and } \\
\text { redistributes energy. Termination } \\
\text { needs SOC information. }\end{array}$ & $\begin{array}{c}\text { The design monitors and } \\
\text { redistributes energy. } \\
\text { Termination needs SOC } \\
\text { information. }\end{array}$ \\
\hline $\begin{array}{c}\text { Number of } \\
\text { PWM } \\
\text { generators }\end{array}$ & 1 per cell & $\begin{array}{c}\text { 2 non overlapping generators (one } \\
\text { for odd and one for even cycles) }\end{array}$ & 1 PWM generator sufficient \\
\hline $\begin{array}{c}\text { Number of } \\
\text { switches }\end{array}$ & 1 per cell & 2 per cell & 1 per group of cells \\
\hline $\begin{array}{c}\text { Thermal } \\
\text { Control } \\
\text { Requirements }\end{array}$ & Very High & Moderate (switches are \\
dissipative) & Low \\
\hline
\end{tabular}

\section{Conclusion}

The various cell balancing techniques have been implemented in MATLAB Simulink and are performing as expected. The RC equivalent model of the lithium-ion cell results in a better analysis of the cell balancing system by considering the thermal effects on the cell. The bleed resistor based passive cell balancing took a very long time to balance. It took more than 16000 seconds to reach a $0.01 \mathrm{~V}$ difference for capacitors with 5F capacitance. The switched capacitor design took 0.5 seconds to reach a $0.01 \mathrm{~V}$ difference in cell voltages for cells modelled as capacitors with $0.001 \mathrm{~F}$. Thus, to compare it with the passive balancing circuit, the resonant switched capacitor circuit would approximately take 500 seconds to reach the same state if it was simulated with a 5F capacitor as cell. The multi-winding flyback active cell balancing system reached a 2\% difference in SOC in 1800 seconds. There was 
a visible increase in time taken for balancing the cells using multi-winding active cell balancing as the cell temperature increased. A $2.32 \%$ increase in time taken was observed when cell temperature increased from 293K to $313 K$.

\section{References}

[1]. Lu, L., Han, X., Li, J., Hua, J. and Ouyang, M. A review on the key issues for lithium-ion battery management in electric vehicles. 2021.

[2]. Huria MCGL. Experimentally-Determined Models for High-Power Lithium Batteries. Advanced Battery Technology 2011, SAE; 2011.

[3]. Jian Cao NSAAE. Battery balancing methods: A comprehensive review. IEEE Vehicle Power and Propulsion Conference; 2008.

[4]. Cell balancing, battery state estimation, and safety aspects of battery management systems for electric vehicles. Advances in Battery Technologies for Electric Vehicles; 2015.

[5]. Van den Bossche AFMAA. A Cell Equalization Method Based on Resonant Switched Capacitor Balancing for Lithium-Ion Batteries. 9th International Conference on Mechanical and Aerospace Engineering; 2018.

[6]. Van Den Bossche AFMAA. An active cell equalization technique for Lithium-Ion batteries based on inductor balancing. 9th International Conference on Mechanical and Aerospace Engineering; 2018.

[7]. Zhang, Lijun \& Peng, Hui \& Ning, Zhansheng \& Zhongqiang, Mu \& Sun, Chang-Yan. Comparative Research on RC Equivalent Circuit Models for Lithium-Ion Batteries of Electric Vehicles. Applied Sciences.

[8]. T. Huria, M. Ceraolo, J. Gazzarri and R. Jackey. High fidelity electrical model with thermal dependence for characterization and simulation of high power lithium battery cells. IEEE International Electric Vehicle Conference; 2012.

[9]. Salmasi MGAF. Estimation of state of charge, unknown nonlinearities, state of health of a lithium-ion battery based on a comprehensive unobservable model. IEEE Trans. Ind. Electron; 2012.

[10]. Van Mierlo M Daowd N Omar P VDBAJ. Passive and active battery balancing comparison based on MATLAB simulation. 2011 IEEE Vehicle Power and Propulsion Conference; 2011.

[11]. Y. Shang, B. Xia, C. Zhang, N. Cui, J. Yang and C. C. Mi. An Automatic Equalizer Based on Forward-Flyback Converter for Series-Connected Battery Strings. IEEE Transactions on Industrial Electronics; 2017.

[12]. Stefanov, Dimo \& Todorova, Teodora \& Valchev, Vencislav. A Flyback Converter Based System for an Active Charge Balancing of Li-Ion Battery Packs. 2018 IEEE XXVII International Scientific Conference Electronics; 2018.

[13]. Jiang B. Active cell balancing algorithms in lithium-ion battery. Chalmers tekniska högskola / Institutionen för elektroteknik; 2020.

[14].Van den Bossche Alex. FMA\&. Flyback Converter Balancing Technique for Lithium Based Batteries. 2019 8th International Conference on Modern Circuits and Systems Technologies; 2019.

[15].C.-H. Kim, M.-Y. Kim, and G.-W. Moon. A modularized chargeequalizer using a battery monitoring ic for series-connected li-ion batterystrings in electric vehicles. IEEE Transactions on Power Electronics; 2013. 